\title{
Lactobacillus salivarius and $L$. gasseri down-regulate Aggregatibacter actinomycetemcomitans exotoxins expression
}

\author{
Lorenzo Nissen • Barbara Sgorbati • Bruno Biavati • \\ Georgios N. Belibasakis
}

Received: 20 November 2012 / Accepted: 11 July 2013 / Published online: 4 August 2013

(C) Springer-Verlag Berlin Heidelberg and the University of Milan 2013

\begin{abstract}
Beneficial microbes, such as lactobacilli establish a symbiosis with the host and confer health-associated effects, by limiting the growth of indigenous pathogens and challenging microbes introduced by altered foods. Nevertheless, there is scarce information on the effects of beneficial microbes on the virulence properties of bacterial species associated with oral diseases, such as periodontitis. Aggregatibacter actinomycetemcomitans is a Gram-negative species highly implicated in the etiology of localized aggressive periodontitis. The objective of this study was to investigate the effect of lactobacilli on the expression of the two major virulence factors of A. actinomycetemcomitans. Lactobacillus salivarius and $L$. gasseri were selected as beneficial species. The gene expressions of leukotoxin $(L t x A)$ and cytolethal distending toxin $(C d t B)$ by $A$. actinomycetemcomitans were analyzed in response to challenge by lactobacilli cell-free supernatants. Neither lactobacilli affected the growth, but strongly attenuated the expressions of both $C d t B$ and $L t x A$ in the two $A$. actinomycetemcomitans strains tested. This reduction of the expression of these two exotoxins was time-dependent. These fundamental findings may indicate that lactobacilli can reduce the virulence of putative opportunistic oral pathogens, and may provide insights to future therapeutic approaches for the respective diseases.
\end{abstract}

Electronic supplementary material The online version of this article
(doi:10.1007/s13213-013-0694-x) contains supplementary material,
which is available to authorized users.

L. Nissen $(\bowtie) \cdot$ B. Sgorbati $\cdot$ B. Biavati

Microbiology Area, Department. Agricultural Sciences, Alma Mater

Studiorum, Università di Bologna, V.le Fanin 44, 40127 Bologna, Italy

e-mail: lorenzo.nissen@unibo.it

G. N. Belibasakis

Oral Microbiology and Immunology, Institute of Oral Biology, Center of Dental Medicine, University of Zürich, Plattenstrasse 11, 8032 Zürich, Switzerland
Keywords Probiotics · Oral cavity $\cdot$ Cytolethal distending toxin - Leukotoxin · Periodontal disease

\section{Introduction}

Microbial ecology has now entered the microbiome era, which is the systemic study of a microbial community as a functional entity (Chen et al. 2010). The Human Microbiome Project of the United States National Institute of Health has set the basis (Turnbaugh et al. 2007), while the Human Oral Microbiome Database (Chen et al. 2010), in particular, is investigating in further detail the specialized ecological niche of the oral cavity. The oral microbiome is one of the most studied in humans, due to the easy accessibility of bacterial samples, and the fact that some species are associated with very frequent human infections with vast socio-economical implications, such as periodontal diseases and dental caries, but also because respiratory and intestinal pathogens may access the respective systems via the oral cavity (Raghavendran et al. 2007; Kuehbacher et al. 2008). Recent evidence demonstrates that the oral cavity hosts approximately 700 prevalent bacterial taxa, with distinct subsets predominating at different habitats (Dewhirst et al. 2010). Nevertheless, not much is known about the related molecular cross-talk and ecological interactions within these habitats. In this respect, a number of studies have investigated host-microbe interactions (Handfield et al. 2005; Hasegawa et al. 2007; Belibasakis et al. 2011a, b), whereas others have focused on the intimate challenge between antagonistic microbial species (Ishikawa et al. 2003). Among these microbes, some take part in disease, while others contribute to maintenance of health (Lazarevic et al. 2009). In principle, the latter could control the virulence of former by specific strategies such as competitive exclusion or displacement. Beneficial bacteria possess different capacities aiming at limiting the growth of neighboring pathogens. For example, bacterial products like bacteriocins 
can exert antimicrobial activity, or even perturb the local microenvironment, by modulating the $\mathrm{pH}$ or $\mathrm{O}_{2}$ content, which would in turn result inhibition of certain pathogens. The disruption of a proper mutualism between commensals and pathogens within a microbial consortium can facilitate the onset of local infections and diseases. Such examples are periodontal diseases and dental caries, which are the most common oral diseases, and among the most prevalent infections in humans. While putative oral pathogens are well described, there is scarce information over the potential oral health-promoting role of indigenous commensals, such as lactobacilli that are reported as beneficial species in other ecological niches, and even used as probiotics supplements. Aggregatibacter actinomycetemcomitans is a Gram-negative facultatively anaerobic opportunistic oral pathogen, which is highly implicated in the etiology of aggressive periodontitis (Henderson et al. 2010; Haubek 2010). The disease is characterized by rapid disease of the tooth-supporting (periodontal) tissues, and affects adolescents and young adults. The main virulence factors of $A$. actinomycetemcomitans are the leukotoxin and the cytolethal distending toxin (Cdt), which are protein exotoxins targeting cells of the immune system or the periodontal tissues. The Cdt can cause growth inhibition and eventually apoptosis to virtually all eukaryotic cells, whereas the leukotoxin can selectively kill human leukocytes, or activate them to produce a strong pro-inflammatory response (Fine et al. 2006). The objective of the present study was to investigate the effect of secreted lactobacilli products on the gene expression of these two virulence factors (namely $L t x A$ and $C d t B$ ) by $A$. actinomycetemcomitans in planktonic culture. The hypothesis is that the beneficial species, lactobacilli in this case, could be able to attenuate or inhibit the expression of the investigated virulence factor genes. This approach may enlighten the relationship(s) between putative periodontal pathogens and lactobacilli that can reside in the oral cavity, with known probiotic capacity for the health of the gastro-intestinal tract (GIT). It may also provide clearer insights to future adjunctive therapeutic approaches for the treatment of periodontitis.

\section{Materials and methods}

Microbial strains and products

Aggregatibacter actinomycetemcomitans OMZ250b (Y4 clone) and OMZ295 (JP2 clone), Lactobacillus salivarius OMZ520 and L. gasseri OMZ525 were obtained from the OMZ culture collection of the Section of Oral Microbiology and Immunology, University of Zürich. Bacteria were cultured on modified Fluid Universal Medium (mFUM) (Guggenheim et al. 2001) under aerobic conditions and $10 \% \mathrm{CO}_{2}$ (HeraCell 240, Heraeus; ThermoFisher Scientific, Bremen, Germany).
Per liter of distilled water, mFUM contained $10 \mathrm{~g}$ tryptone, $5 \mathrm{~g}$ yeast extract, $3 \mathrm{~g}$ glucose, $2 \mathrm{mg}$ hemin, $1 \mathrm{mg}$ menadione, $0.5 \mathrm{~g}$ cysteine hydrochloride, $2 \mathrm{~g} \mathrm{NaCl}, 0.5 \mathrm{~g} \mathrm{Na}_{2} \mathrm{CO}_{3}, 1 \mathrm{~g} \mathrm{KNO}_{3}$, $0.9 \mathrm{~g} \mathrm{~K}_{2} \mathrm{HPO}_{4}, 0.9 \mathrm{~g}$ of $\left(\mathrm{NH}_{4}\right)_{2} \mathrm{SO}_{4}$, and $0.18 \mathrm{~g} \mathrm{MgSO}_{4} \cdot 7 \mathrm{H}_{2} 0$, supplemented with $67 \mathrm{mmol}$ Sorensen's buffer, at a pH of 7.2. A. actinomycetemcomitans strains OMZ250b (Y4 clone) and OMZ295 (JP2 clone) used in this study were cultured in mFUM supplemented with $0.3 \%$ glucose at $37{ }^{\circ} \mathrm{C}$ for $48 \mathrm{~h}$. L. salivarius OMZ520 and L. gasseri OMZ525 were also cultured in $\mathrm{mFUM}$, which was instead supplemented with $0.15 \%$ glucose and $0.15 \%$ sucrose at $37{ }^{\circ} \mathrm{C}$ for $24 \mathrm{~h}$. The density of each bacterial strain in culture was quantified with a spectrophotometer at $\mathrm{OD}_{600}$ (U 2000, Hitachi; BoehringerMannheim, Rotkreuz, Switzerland) and CFU/ml were defined by plotting the OD against an established bacterial growth curve. After a 24-h period of growth, the lactobacilli suspension cultures were harvested, their density was measured, and the cultures were thereafter centrifuged. The cell pellet was discarded and the cell-free supernatants were then buffered with a $10 \% \mathrm{v} / \mathrm{v}$ of PBS $(\mathrm{pH} 7)$, filter-sterilized $(0.22 \mu \mathrm{m})$ before being used in the experimentations with A. actinomycetemcomitans at dilutions corresponding to lactobacilli concentrations of $10^{4} \mathrm{CFU} / \mathrm{ml}$.

\section{Microbial interactions}

Aggregatibacter actinomycetemcomitans strain OMZ295 or OMZ250b cultures in the exponential growth phase were used at a concentration of $10^{7} \mathrm{CFU} / \mathrm{ml}$. These were cultured in fresh $\mathrm{mFUM}$, in the presence or absence of $10^{4} \mathrm{CFU} / \mathrm{ml}$ lactobacilli cell-free supernatants $(10 \% \mathrm{v} / \mathrm{v})$. After 3 and $6 \mathrm{~h}$ of incubation, bacterial density was quantified at $\mathrm{OD}_{600}$, and the $A$. actinomycetemcomitans bacterial cells in culture were harvested by centrifugation, and their total RNA content was isolated.

RNA isolation and cDNA synthesis

Cells were lysed with $400 \mu \mathrm{g} / \mathrm{ml}$ of Lysozyme in TE solution, at room temperature for $10 \mathrm{~min}$. RNA was isolated with RNeasy mini kit and Bacteria Protect reagent (Qiagen, Hilden, Germany). RNA yield and purity was determined with a NanoDrop spectophotometer (ThermoFisher Scientific). The isolated total RNA samples exhibited a $\lambda 260 / \lambda 280$ between 1.8 and 2.2. This was then reversed transcribed into cDNA, by using Moloney murine leukemia virus reversetranscriptase enzyme (M-MLV RT RNase H minus) (Promega, Madison, Wi, USA). Briefly, $1 \mu \mathrm{g}$ of total RNA was incubated with $0.5 \mu \mathrm{g} / \mathrm{ml}$ of Oligo $(\mathrm{dT})_{15}$ primer (Promega) at $70{ }^{\circ} \mathrm{C}$ for $5 \mathrm{~min}$ and cooled on ice. A master mix was added to the samples, comprising $10 \mathrm{mM}$ dNTPs, 200 units of M-MLV RT enzyme and buffer (Promega), and nuclease-free water to a final volume of $25 \mu \mathrm{l}$. For the reverse- 
transcription reaction, these samples were incubated at $40^{\circ} \mathrm{C}$ for $60 \mathrm{~min}, 70{ }^{\circ} \mathrm{C}$ for $15 \mathrm{~min}$, and cooled to $4{ }^{\circ} \mathrm{C}$ on a PCR apparatus (Biometra, Goettingen, Germany). The products obtained were then stored at $-20{ }^{\circ} \mathrm{C}$ until further analysis by qPCR for relative quantification of gene expression.

Quantitative real time polymerase chain reaction (qPCR)

Gene expressions of CdtB subunit of Cdt, LtxA subunit for leukotoxin and GlyA (glycine/serine hydroxymethyl transferase A) for the endogenous control were analyzed using an ABI Prism7000 Sequence Detection System (Applied Biosystems, Foster City, CA, USA), and coupled with SYBR Green Master Mix (Applied Biosystems). The CdtB gene oligonucleotide primers were designed using Primers Express 3.0 software (Applied Biosystems) and the sequences were: forward: 5'-GGGCAAACCGAGTGAACTTA-3', and reverse: 5'-CTCGTCTTTCCGGTGATGAT-3'. Primers sequences for LtxA and GlyA endogenous control were obtained from the literature. For GlyA gene, the sequences were: forward: 5'-CCCAATTCACCAACAAATATGC-3', and reverse: 5'-ATTCTTTCGCACGCTCAATAG-3' (Isaza et al. 2008). For the LtxA gene, the sequences were: forward: 5'-GTGCTAGGTAAACATCGGTAAAG-3', and reverse 5'GACCACAGAGGCAATTAACC-3' (Isaza et al. 2008). Before proceeding to the quantification reactions, the specificity of each primer pair was evaluated with the melt-curve analysis software of the Prism7000 Sequence Detection System (Applied Biosystems). The selected primers pairs showed no nonspecific peaks. Calculation of expression values for each gene was performed by the $2^{-\Delta \mathrm{Ct}}$ method, calibrated against the expression of GlyA endogenous control that was found to be consistently expressed under all conditions. Cycle threshold is abbreviated as $\mathrm{Ct}$ and the $\Delta \mathrm{Ct}$ calculation was as follows: $\mathrm{Ct}(+\mathrm{RT})-\mathrm{Ct} \quad(-\mathrm{RT})=\mathrm{cCt} \quad($ corrected $\mathrm{CT})$. $\Delta \mathrm{Ct}=\mathrm{cCt}($ targetgene $)-\mathrm{cCt}($ endogenouscontrolgene, GlyA) (Belibasakis et al. 2011a, b).

Statistic analysis

Experiments were performed at least three times to ensure reproducibility of results. The results are reported as means \pm standard deviations (SD). A two-way ANOVA followed by Tukey's test were used for statistical comparisons, and $P<0.05$ was considered statistically significant.

\section{Results}

The growth of $A$. actinomycetemcomitans was not inhibited when cultured in the presence of cell-free lactobacilli culture supernatants, over the 6-h experimental period (Table 1). Nevertheless, the expression of CdtB and LtxA genes was attenuated in both $A$. actinomycetemcomitans strains, when cultured in the presence of lactobacilli cell-free supernatants. Supernatants from both $L$. salivarius and L. gasseri were capable to down-regulate CdtB and LtxA gene expressions, but in different manners.

\section{Relative expression of $C d t B$ subunit}

The attenuation of $\mathrm{CdtB}$ gene expression of $A$. actinomycetemcomitans OMZ295 (Fig. 1) was evident at $3 \mathrm{~h}$, and mainly when exposed to L. salivarius supernatant. At this early time-point, L. salivarius significantly down-regulated CdtB expression by more than 4-fold compared to the control. On the other hand, L. gasseri was slightly less potent in this effect, by causing a less than 3-fold down-regulation, in comparison to the respective control. This attenuation of $\mathrm{CdtB}$ expression was maintained over $6 \mathrm{~h}$ in the presence of $L$. salivarius, but partly resumed the levels of the untreated $A$. actinomycetemcomitans control in the presence of L. gasseri. In the case of $A$. actinomycetemcomitans strain OMZ250b, both $L$. gasseri and L. salivarius supernatants inhibited CdtB expression as early as $3 \mathrm{~h}$, by approximately 3 -fold compared to the control (Fig. 1). After $6 \mathrm{~h}$, the attenuation of $\mathrm{CdtB}$ expression was persistent in the presence of either $L$. salivarius or L. gasseri, which was in both cases more than 2-fold lower compared to the control.

\section{Relative expression of the LtxA subunit}

The expression of LtxA was further investigated. In the case of A. actinomycetemcomitans strain OMZ295, LtxA expression was already reduced at $3 \mathrm{~h}$ in the presence of $L$. salivarius compared to the untreated control, and this attenuation was

Table 1 Growth of A. actinomycetemcomitans strain OMZ250b and OMZ295 for up to $6 \mathrm{~h}$ in the presence of lactobacilli cell-free culture supernatants

\begin{tabular}{llll}
\hline Strain & \multicolumn{3}{c}{ Bacterial growth at $\mathrm{OD}_{600}$} \\
\cline { 2 - 4 } & $0 \mathrm{~h}^{\mathrm{a}} 3 \mathrm{~h}$ & $6 \mathrm{~h}$ \\
\hline $\begin{array}{l}\text { A. actinomycetemcomitans } \mathrm{OMZ} \\
\quad 0.4\end{array}$ & $0.455 \pm 0.035$ & $0.77 \pm 0.028$ \\
$\begin{array}{l}\text { 250b alone } \\
\text { L. salivarius OMZ 520 }\end{array}$ & 0.4 & $0.45 \pm 0.014$ & $0.645 \pm 0.007$ \\
+ L. gasseri OMZ 525 & 0.4 & $0.435 \pm 0.021$ & $0.67 \pm 0.084$ \\
A. actinomycetemcomitans $\mathrm{OMZ}$ & 0.4 & $0.46 \pm 0.014$ & $0.665 \pm 0.022$ \\
$\quad$ 295 alone & 0.4 & $0.45 \pm 0.015$ & $0.615 \pm 0.014$ \\
+ L. salivarius OMZ 520 & 0.4 & $0.44 \pm 0.007$ & $0.525 \pm 0.049$ \\
\hline L. gasseri OMZ 525 & & & \\
\hline
\end{tabular}

${ }^{\mathrm{a}}$ Starting bacterial inoculum. 
Fig. 1 Effect of lactobacilli cellfree culture supernatants on $C d t B$ expression in $A$.

actinomycetemcominats

OMZ295 and OMZ250b, measured by qRT-PCR.

*,**Statistically significant difference $(P<0.05)$, compared to the untreated $A$.

actinomycetemcomitans OMZ295 and OMZ250b controls, at the corresponding time-points

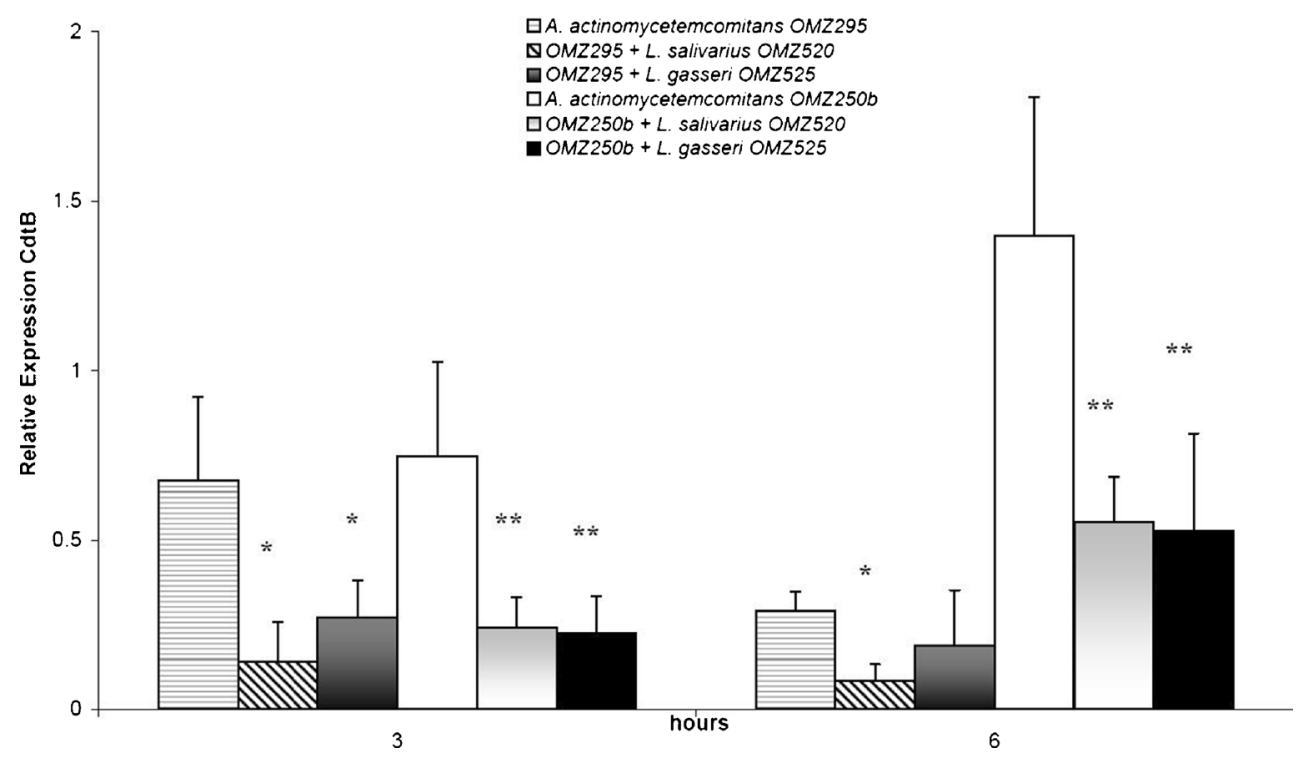

maintained over $6 \mathrm{~h}$ (Fig. 2). On the contrary, in the presence of $L$. gasseri, LtxA expression was not significantly affected after $3 \mathrm{~h}$, but at $6 \mathrm{~h}$ this was significantly down-regulated compared to the control, and to a similar extent as in the case of L. salivarius (Fig. 2). The effect of lactobacilli supernatants on LtxA expression was also investigated in A. actinomycetemcomitans strain OMZ250b. LtxA expression in this strain after $3 \mathrm{~h}$ was already significantly down-regulated in the presence of either lactobacilli species, and this effect persisted over $6 \mathrm{~h}$ (Fig. 2). L. gasseri was more potent than L. salivarius in attenuating LtxA expression, particularly after $3 \mathrm{~h}$ of A. actinomycetemcomitans OMZ250b culture.

\section{Discussion}

The ability of lactobacilli and other lactic acid bacteria (LAB) to colonize the oral cavity and in particular the periodontium is still debated. Some lactobacilli are indigenous and inhabit the oral cavity of the newborn as they are transferred from the mother (e.g., Lactobacillus vaginalis and the bifidobacteria
Fig. 2 Effect of lactobacilli cellfree culture supernatants on LtxA expression in $A$. actinomycetemcominats OMZ295 and OMZ250b, measured by qRT-PCR. $*, * *$ Statistically significant differences $(P<0.05)$, compared to the untreated $A$. actinomycetemcomitans OMZ295 and OMZ250b controls, respectively, at the corresponding time-points

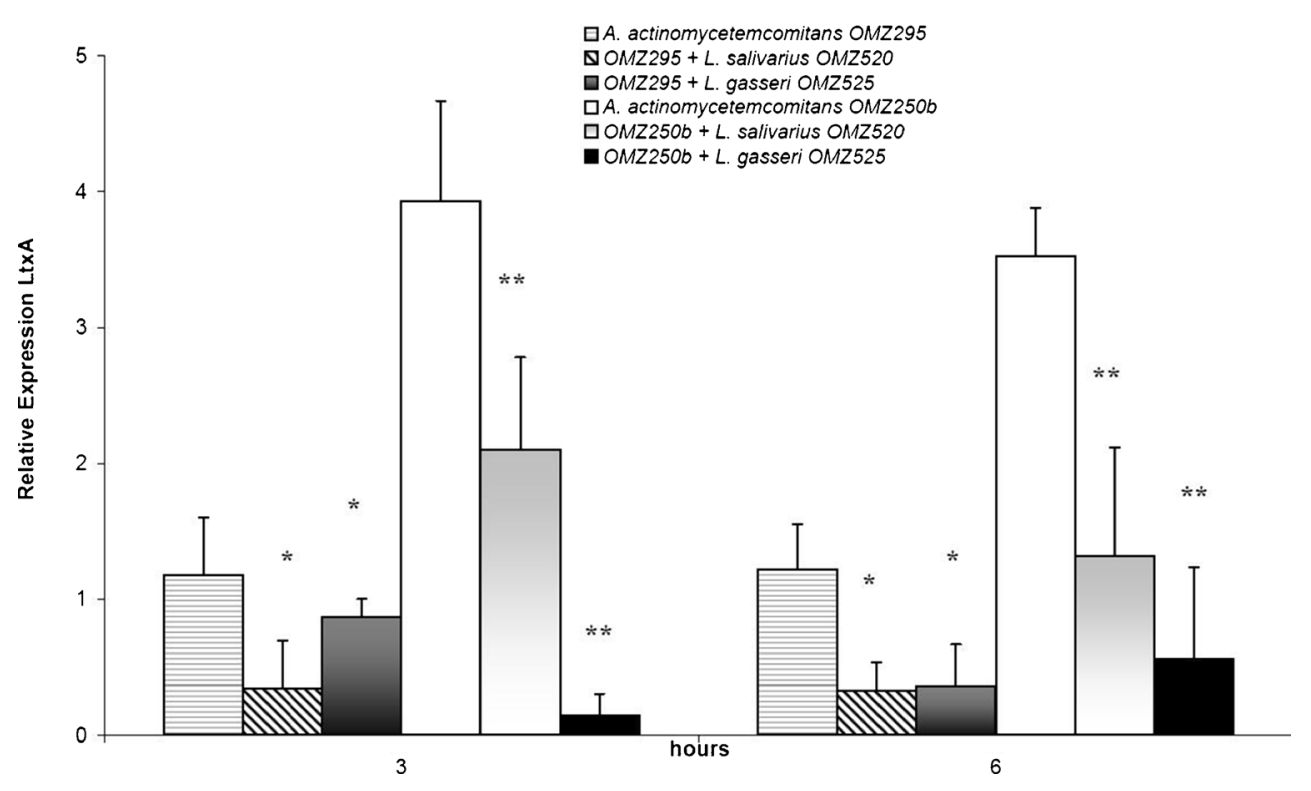


group). This phenomenon is not restricted to the oral cavity, but is generalized to the whole human body. As happens for the GIT, the skin, and for several mucosas, the first bacteria to settle and colonize these niches are mainly bifidobacteria, but even include lactobacilli and other LAB species. Most of these are considered probiotic, or at least not harmful, commensals. This study aimed to identify if oral lactobacilli, with proven probiotic capability in the GIT, are able to attenuate or inhibit the gene expression of the two major exotoxins (virulence factors) of the putative periodontal pathogen A. actinomycetemcomitans. The selection of $L$. salivarius and $L$. gasseri as putative oral probiotics was justified by their detection in the composition of the microbiota of the periodontium, primarily at healthy sites, compared to sites affected by periodontitis (Koll-Klais et al. 2005; Hojo et al. 2007; Badet and Thebaud. 2008; Pham et al. 2009). Concerning $L$. salivarius, there are reports proposing that this species could act as putative probiotic for the periodontium (Shimauchi et al. 2008; Mayanagi et al. 2009; Iwamoto et al. 2010). To date, considering the limited number of papers dealing with this issue, L. salivarius is perhaps the best characterized indigenous putative probiotic species inhabiting the oral cavity. While some authors have reviewed and supported the health benefits of probiotics in the oral cavity (Meurman and Stamatova. 2007; Stamatova and Meurman. 2009), it is of interest to mention that some studies have described lactobacilli (Mantzourani et al. 2009a, b), and in particular $L$. salivarius, in association with caries (Matsumoto et al. 2005). Another study has shown in an in vitro model that L. salivarius decreased the numbers of black pigmented anaerobic rods that are associated with periodontitis (Ishikawa et al. 2003). Notwithstanding, there are no studies on the molecular cross-talk between lactobacilli or their products on the virulence mechanisms of putative oral pathogens. Lactobacillus gasseri was selected for the present experimental system mainly based on recent findings that outlined this species as one of the most potent among a set of new isolates of putative probiotic/beneficial bacteria (Nissen et al. 2009; Kawase et al. 2011). Considering all these aspects, to our knowledge the present study is one of the first that has addressed the effects of lactobacilli on the expression of virulence factors of any putative oral pathogen. Both lactobacilli species tested in this study demonstrated promising results in competition with the putative periodontal pathogen A. actinomycetemcomitans. The attenuation of gene expression of the two toxins appears to be visible as early as $3 \mathrm{~h}$, and is not commensurate with a reduction of $A$. actinomycetemcomitans growth. The effect on LtxA expression appeared to be more time-dependent than that on $\mathrm{CdtB}$ expression. The present results also demonstrate that both of the tested A. actinomycetemcomitans strains, namely OMZ250b (which is a Y4 clone) and OMZ295 (which is a JP2 clone), are sensitive to the presence of lactobacilli supernatants, even though the JP2 clone generally exhibits higher toxin activity than the Y4 clone (Kawamoto et al. 2009).

The ecological complexity of the oral cavity environment is partly attributed to interrelationships between different species (i.e. synergistic or antagonistic), which are subject to changes due to food intake and diet habits. Indeed, the oral microbiome is in constant exposure to the products of the cud, which can directly affect its ecology. In this complex environment, an equilibrium ratio of beneficial and pathogenic microbes is essential: to prevent the establishment of dental caries or periodontal diseases, and to potentially reduce the emanation of bacterial toxins further distally into the GIT. The mechanism by which the cell-free supernatants of the lactobacilli tested are able to affect mRNA expression of $A$. actinomycetemcomitans virulence factors is unknown. Nevertheless, the present findings that lactobacilli at densities as low as $10^{4} \mathrm{CFU} / \mathrm{ml}$ can elicit an adequate effect on reducing the expressions of leukotoxin and $\mathrm{Cdt}$ is encouraging, since it demonstrates that a high probiotic load is not necessary for potential therapies. It is otherwise well documented that $\mathrm{LAB}$ species are able to produce a class of molecules with antimicrobial capability. For instance, bacteriocins produced by $L$. gasseri are able to inhibit enteric pathogens (Itoh et al. 1995; Alpay Karaoglu et al. 2003). Moreover, bacteriocins produced by $L$. salivarius are able to inhibit the growth of clinical Staphylococcus aureus isolates (Robredo and Torres. 2000), as well as Listeria monocytogenens (Corr et al. 2007). The effect of this class of molecules and other antimicrobial factors produced by lactobacilli is inhibitory against bacterial pathogens at a certain dosage, but the effect of minimal doses remains unclear. Recently, it was reported that sub-lethal dosage of different antimicrobials could down-regulate the expression of virulence genes of bacterial pathogens, such as Vibrio cholerae (Chatterjee et al. 2010; Yamasaki et al. 2011) and Staphylococcus aureus (Smith-Palmer et al. 2004; Qiu et al. 2011), without inhibiting their growth. This action could reflect the effects observed in the present work in $A$. actinomycetemcomitans.

The results obtained in this study indicate that probiotic species (i.e. lactobacilli) may reduce the virulence capacities of putative oral pathogens, at least as judged by the effects on $A$. actinomycetemcomitans. This observation could be useful to produce an application able to control or eradicate the presence of putative periodontal pathogens in the periodontium. The possibility to manage oral diseases with a natural, non-invasive and non-stressful method is particularly appealing, and may prevent problems related to pharmacological treatments, such 
as the use of antibiotics. Last, but not least, the use of cell-free supernatants instead of viable bacteria is an added value for wider and easier application, particularly for these diseases embracing the immune system in order to prevent the continuous antigenic load.

Acknowledgments The work was supported by a Grant of "XVI Programma Marco Polo" (Alma Mater Studiorum - University of Bologna) and by the Institute of Oral Biology (University of Zürich). The authors would also like to thank Mrs. E. Plattner for her technical assistance.

Disclosure All authors declare that they have no conflict of commercial or financial interest.

\section{References}

Alpay Karaoglu S, Aydin F, Kilic SS, Kilic AO (2003) Antimicrobial activity and characteristics of bacteriocins produced by vaginal lactobacilli. Turk J Med Sci 33:7-13

Badet C, Thebaud NB (2008) Ecology of lactobacilli in the oral cavity: a review of literature. Open Microbiol J 2:38-48

Belibasakis GN, Reddi D, Bostanci N (2011a) Porphyromonas gingivalis induces RANKL in T-cells. Inflammation 34(2):133-138

Belibasakis GN, Meier A, Guggenheim B, Bostanci N (2011b) Oral biofilm challenge regulates the RANKL- OPG system in periodontal ligament and dental pulp cells. Microb Pathog 50(1):6-11

Chatterjee S, Asakura M, Chowdhury N, Neogi SB, Sugimoto N, Haldar S, Awasthi SP, Hinenoya A, Aoki S, Yamasaki S (2010) Capsaicin, a potential inhibitor of cholera toxin production in Vibrio cholerae. FEMS Microbiol Lett 306(1):54-60

Chen T, Yu W-H, Izard J, Baranova OV, Lakshmanan A, Dewhirst FE (2010) The human oral microbiome database: a web accessible resource for investigating oral microbe taxonomic and genomic information. Database No. doi:10.1093/DATABASE/BAQ013

Corr SC, Li Y, Riedel CU, O’Toole PW, Hill C, Gahan CGM (2007) Bacteriocin production as a mechanism for the anti-infective activity of Lactobacillus salivarius UCC118. Proc Natl Acad Sci USA 104(18):7617-7621

Dewhirst FE, Chen T, Izard J, Paster BJ, Tanner ACR, Yu W-H, Lakshmanan A, Wade WG (2010) The human oral microbiome. J Bacteriol 192(19):5002-5017

Fine DH, Kaplan JB, Kachlany SC, Schreiner HC (2006) How we got attached to Actinobacillus actinomycetemcomitans: a model for infectious diseases. J Periodontol 42:114-157

Guggenheim B, Giersten E, Schupbach P, Shapiro S (2001) Validation of an in vitro biofilm model of supragingival plaque. J Dent Res 80(1):363-370

Handfield M, Mans JJ, Zheng G, Lopez MC, Mao S, Progulske-Fox A, Narasimhan G, Baker HV, Lamont RJ (2005) Distinct transcriptional profiles characterize oral epithelium microbiota interactions. Cell Microbiol 7(6):811-823

Hasegawa Y, Mans JJ, Mao S, Lopez MC, Baker HV, Handfield M, Lamont RJ (2007) Gingival epithelial cell transcriptional responses to commensal and opportunistic oral microbial species. Infect Immun 75:2540-2547

Haubek D (2010) The highly leukotoxic JP2 clone of Aggregatibacter actinomycetemcomitans: evolutionary aspects, epidemiology and etiological role in aggressive periodontitis. APMIS Suppl 130:1-53

Henderson B, Ward JM (2000) Ready D (2010) Aggregatibacter (Actinobacillus) actinomycetemcomitans: a triple A periodontopathogen? Periodontology 54(1):78-105
Hojo K, Mizoguchi C, Taketomo N, Ohshima T, Gomi K, Arai T, Maeda N (2007) Distribution of salivary Lactobacillus and Bifidobacterium species in periodontal health ad disease. Biosci Biotech Biochem 71(1):152-157

Isaza MP, Duncan MS, Kaplan JB, Kachlany SC (2008) Screen for Leukotoxin mutants in Aggregatibacter actinomycetemcomitans: genes of the phosphotransferase system are required for Leukotoxin biosynthesis. Infect Immun 76(8):3561-3568

Ishikawa H, Aiba Y, Nakanishi M, Oh-Hashi Y, Koga T (2003) Suppression of periodontal pathogenic bacteria in the saliva of humans by the administration of Lactobacillus salivarius TI2711. J Jpn Assoc Periodontol 45(1):105-112

Itoh T, Fujimoto Y, Kawai Y, Toba T, Saito T (1995) Inhibition of foodborne pathogenic bacteria by bacteriocins from Lactobacillus gasseri. Lett Appl Microbiol 21:137-141

Iwamoto T, Suzuki N, Tanabe K, Takeshita T, Hirofuji T (2010) Effects of probiotic Lactobacillus salivarius WB21 on halitosis and oral health: an open-label pilot trial. Oral Surg Oral Med Oral Pathol Oral Radiol Endod 110:201-208

Kawamoto D, Ando ES, Longo PL, Nunes ACR, Wikstrom M, Mayer MPA (2009) Genetic diversity and toxic activity of Aggregatibacter actinomycetemcomitans isolates. Oral Microbiol Immunol 24(6):493501

Kawase M, He F, Kubota A, Miyazawa K, Yoda K, Hiramatsu M (2011) Strain-specific detection by pulsed- field gel electrophoresis of Lactobacillus gasseri TMC0356 in human faeces after oral administration of these organisms. Microbiol Immunol 55(8):589-594

Koll-Klais P, Mandar R, Leibur E, Marcotte H, Hammarstrom L, Mikelsaar M (2005) Oral lactobacilli in chronic periodontitis and periodontal health: species composition and antimicrobial activity. Oral Microbiol Immunol 20(6):354-361

Kuehbacher T, Rehman A, Lepage P, Hellmig S, Folsch UR, Schreiber S, Otto SJ (2008) Intestinal TM7 bacterial phylogenies in active inflammatory bowel disease. J Med Microbiol 52(12):1569-1576

Lazarevic V, Whiteson K, Huse S, Hernandez D, Farinelli L, Osteras M, Schrenzel J, Francois P (2009) Metagenomic study of the oral microbiota by Illumina high-throughput sequencing. J Microbiol Methods 79(3):266-271

Mantzourani M, Gilbert SC, Su Long HNH, Sheehy EC, Tank S, Fenlon M, Beighton D (2009a) The isolation of bifidobacteria from occlusal carious lesions in children and adults. Caries Res 43(4):308-313

Mantzourani M, Fenlon M, Beighton D (2009b) Association between Bifidobacteriaceae and the clinical severity of root caries lesions. Oral Microbiol Immunol 24(1):32-37

Matsumoto M, Tsuji M, Sasaki H, Fujita K, Nomura R, Nakano K, Shintani S, Oshima T (2005) Cariogenicity of the probiotic bacterium Lactobacillus salivarius in rats. Caries Res 39(6):479-483

Mayanagi G, Kimura M, Nakayama S, Hirata H, Sakamoto M, Benno Y, Shimauchi H (2009) Probiotics effect of orally administered Lactobacillus salivarius WB21-containing tablets on periodontipathic bacteria: a double-blinded, placebo-controlled, randomized clinical trial. J Clin Periodontol 36:506-513

Meurman JH, Stamatova I (2007) Probiotics: contributions to oral health. Oral Dis 13(5):443-451

Nissen L, Chingwaru W, Biavati B, Sgorbati B, Cencic A (2009) Gut health promoting activity of new putative probiotic/protective $\mathrm{Lac}$ tobacillus spp. strains: a functional study in the small intestinal cell model. Int J Food Microbiol 135(3):288-294

Pham LC, van Spanning RJM, Roling WFM, Prosperi AC, Terefework Z, ten Cate JM, Crielaard W, Zaura E (2009) Effects of probiotic Lactobacillus salivarius W24 on the compositional stability of oral microbial communities. Arch Oral Microbiol 54(2):132-137

Qiu J, Zhang X, Luo M, Li H, Dong J, Wang J, Leng B, Wang X, Feng H, Ren W, Deng X (2011) Sub- inhibitory concentrations of perilla oil affect the expression of secreted virulence factor genes in Staphylococcus aureus. PLoS ONE 6(1):e16160. doi:10.1371/journal.pone.0016160 
Raghavendran K, Mylotte JM (2000) Scannapieco FA (2007) Nursing home-associated pneumonia, hospital- acquired pneumonia and ventilator-associated pneumonia: the contribution of dental biofilms and periodontal inflammation. Periodontology 44:164-177

Robredo B, Torres C (2000) Bacteriocin production by Lactobacillus salivarius of animal origin. J Clin Microbiol 38(10):3908-3909

Shimauchi H, Mayanagi G, Nakaya S, Minamibuchi M, Ito Y, Yamaki K, Hirata H (2008) Improvement of periodontal condition by probiotics with Lactobacillus salivarius WB21: a randomized, double- blind, placebo-controlled study. J Clin Periodontol 35:897-905
Smith-Palmer A, Stewart J, Fyfe L (2004) Influence of sub-inhibitory concentrations of plant essential oils on the production of enterotoxins A and B and $\alpha$-toxin by Staphylococcus aureus. J Med Microbiol 53:1023-1027

Stamatova I (2000) Meurman JH (2009) Probiotics and periodontal disease. Periodontology 51:141-151

Turnbaugh PJ, Ley RH, Hamady M, Fraser-Liggett CM, Knight R, Gordon JI (2007) The human microbiome project. Nature 449:804-811

Yamasaki S, Asakura M, Neogi SB, Hinenoya A, Iwaoka E, Aoki S (2011) Inhibition of virulence potential of Vibrio cholerae by natural compounds. Indian J Med Res 133(2):232-239 